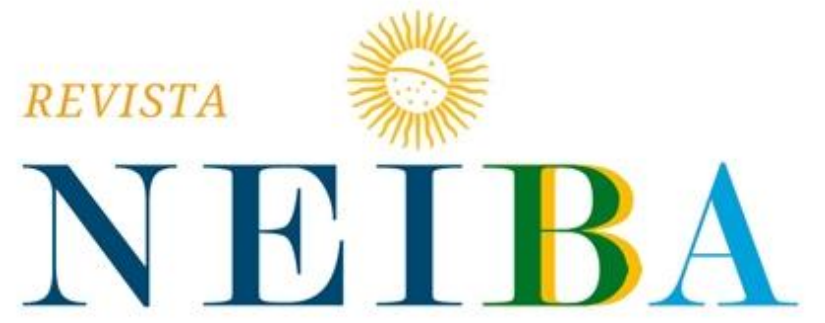

CADERNOS ARGENTINA-BRASIL

\title{
A POLITICA EXTERNA DOS ESTADOS UNIDOS PARA A VENEZUELA: MUDANÇAS E CONTINUIDADES ENTRE OS GOVERNOS BUSH E OBAMA
}

US Foreign Policy Toward Venezuela: Changes and Continuities Throughout Bush's and Obama's Administrations

Gabriela Dorneles Ferreira da Costa ${ }^{1}$

${ }^{1}$ San Tiago Dantas (UNESP, UNICAMP, PUC-SP), São Paulo, SP, Brasil. E-mail: gabrielaferreiradacosta@gmail.com ORCID: https://orcid.org/0000-0002-1967-1467

Recebido em: 14 jan. 2020 | Aceito em: 23 jan. 2020. 


\section{RESUMO}

Diante do desafio representado aos EUA pela ascensão de Hugo Chávez à presidência da Venezuela, analisa-se o histórico da política externa dos Estados Unidos da América (EUA) para a Venezuela desde o início dos anos 2000. O objetivo é verificar as mudanças e as continuidades da política externa dos EUA para a Venezuela conforme as mudanças de governo estadunidense e o contexto político venezuelano no período recente. Para tanto, a análise compreende os governos de George W. Bush (2001-2009) e Barack H. Obama (2009-2017). Nesse ínterim, o trabalho situa a política dos respectivos governos a três conjunturas venezuelanas: a tentativa de golpe de Estado contra Hugo Chávez em 2002, a consolidação do discurso antiestadunidense do governo chavista e a eclosão da crise generalizada instaurada na Venezuela após a morte de Chávez em 2013.

Palavras-chave: Estados Unidos, Política Externa, Venezuela.

\section{ABSTRACT}

In face of the challenge posed to the US by the rise of Hugo Chávez to Venezuela's presidency, this study aims to analyze the historical pattern of US foreign policy toward Venezuela since early 2000s. It seeks to verify shifts and continuities of US foreign policy toward Venezuela considering US government changes and Venezuelan political context. Therefore, the analysis comprises George W. Bush's (2001-2009) and Barack H. Obama's (2009-2017) administrations. Through this period, the research encompasses three different Venezuelan contexts: the Coup D'état attempt in 2002, the consolidation of Chávez's government and his anti-American discourse e the outbreak of the crisis after Chávez's death in 2013.

Keywords: United States, Foreign Policy, Venezuela. 


\section{INTRODUÇÃO}

A Venezuela foi importante aliado dos Estados Unidos da América (EUA) no subcontinente sul-americano durante a maior parte do século XX, especialmente em virtude das relações econômico-comerciais calcadas na produção venezuelana de petróleo. Já em 1999, a eleição de Hugo Chávez na Venezuela representou um desafio para os EUA no que se refere à sua atuação na América do Sul e às relações bilaterais propriamente ditas. O afloramento de um discurso antiestadunidense fundamentado em acusações de imperialismo e o vai-e-vem de tensões domésticas suscitadas pelo populismo de esquerda foram alguns dos elementos presentes ao longo dos governos chavistas. Por sua vez, os EUA, no decorrer dos anos 2000 e 2010, tiveram variação no perfil de sua atuação internacional conforme a administração vigente, oscilando entre posturas mais engajadas e comportamentos mais retraídos.

À vista disso, levanta-se a seguinte questão: houve um padrão de política externa dos EUA para a Venezuela chavista? A partir dessa problematização, tem-se como objetivo verificar quais foram as mudanças e as continuidades da política externa dos EUA para a Venezuela conforme as mudanças de governo estadunidense e o contexto político venezuelano no período recente. Para tanto, a análise compreende os governos de George W. Bush (2001-2009) e de Barack H. Obama (2009-2017). A hipótese adotada é a de que as filiações partidárias e as orientações de política externa diferentes de Bush e de Obama não implicaram mudanças no cerne da política externa dos EUA para a Venezuela (indicando certos níveis de continuidade), mas que alterações conjunturais - tanto nos EUA quanto na Venezuela - no decurso de ambos os governos provocaram ajustes na diplomacia exercida pelos EUA em direção à Venezuela (períodos de mudanças).

A principal contribuição dessa pesquisa é relacionar as transformações políticas domésticas dos dois países para se obter um panorama mais completo das variáveis que incidiram sobre a condução da política externa dos EUA para a Venezuela. Um outro aspecto pelo qual a pesquisa se destaca é a utilização metodológica de conjunturas críticas, identificadas como sendo aquelas fulcrais para os desdobramentos 
da formulação de política externa. Ainda do ponto de vista metodológico, emprega-se análise qualitativa e adota como técnica de pesquisa revisão bibliográfica. Como material de pesquisa, além de livros e artigos científicos, foram consultados relatórios do Congressional Research Service (CRS) e notícias de jornais.

A análise está organizada em duas seções de desenvolvimento além da introdução e da conclusão. Na primeira seção, é explorada a política externa dos EUA para a Venezuela durante o governo Bush, situando essa política nas seguintes conjunturas críticas: a política externa dos EUA pós-atentados de 11 de setembro de 2001, a tentativa de golpe de Estado contra Hugo Chávez em 2002 e a consolidação do governo chavista na Venezuela ao longo da primeira década do século XXI. Na seção seguinte, é analisada a questão sob a administração Obama, compreendendo as conjunturas de relações com a América Latina no pós-crise econômica de 2008 e a relação com a Venezuela em dois momentos: o final do governo Chávez e a eclosão da crise generalizada instaurada após o seu falecimento.

Nesse sentido, para analisar a política externa empregada pelos EUA é necessário, primeiramente, compreender o que significou a ascensão do chavismo na Venezuela. De meados ao final do século XX, EUA e Venezuela mantiveram relações de cordialidade. Durante boa parte desse período, a Venezuela era considerada país politicamente estável na América do Sul, despertando pouca preocupação estadunidense. Essa visão passou a mudar em 1989, quando a Venezuela enfrentou uma série de protestos conhecida como Caracazo, e foi reforçada quando, em 1992, o então tenente-coronel Hugo Rafael Chávez Frias liderou uma tentativa de golpe contra o presidente Carlos Andrés Pérez (Romero, 2006). Esse golpe de Estado fracassado foi o impulso de Hugo Chávez à política. A partir daquele momento, Chávez ganhou popularidade e, então, optou pela disputa política pela via democrática (Lapper, 2006). Em dezembro de 1998 a Venezuela elegeu Hugo Chávez para a presidência da nação.

Na presidência, Chávez constituiu um fenômeno complexo conhecido como "chavismo", uma mistura de movimento político e de doutrina de governo. Vieira (2016) elenca alguns dos principais elementos constitutivos apontados pela literatura, cada qual enfocando aspectos específicos (econômico, político, institucional etc.) desse 
fenômeno multifacetado. O primeiro componente do chavismo é o populismo, marca da liderança pessoal e do carisma de Chávez; o segundo é o conceito de "socialismo do século XXI", uma categoria criada para abarcar a concepção de um programa de desenvolvimento econômico e social alternativo na atualidade; o terceiro elemento é o anti-imperialismo, fundamentado no posicionamento político-ideológico de esquerda e aspecto base da política externa de seus governos; o quarto elemento é o bonapartismo, entendido como centralização política no Executivo; e, por último, a ideia de capitalismo de Estado, uma relação entre estrutura e processos econômicos vinculada diretamente ao controle estatal (Vieira, 2016, pp. 18-19). Conforme a autora, todos esses componentes estiveram presentes de forma mais ou menos notória desde que Chávez assumiu o governo em 2 de fevereiro de 1999. Dessa forma, o chavismo foi “[...] uma síntese de múltiplas determinações, o qual não seria apreendido em sua totalidade se nos prendêssemos em um ou outro conceito político na tentativa de caracterizá-lo" (Vieira, 2016, p. 205).

Esses atributos do chavismo colocaram a Venezuela na rota de choque com Washington. Essa trajetória de embate com os EUA foi, na realidade, uma política deliberada de Caracas como ferramenta de autoafirmação do governo e de busca pela consecução dos interesses de sua diplomacia. No âmbito de sua política externa, a Venezuela empregou soft balancing contra os EUA (especialmente através da aproximação com Cuba, China, Rússia e Irã) e uma nova estratégia intitulada "diplomacia do poder social", na qual Caracas empregava elementos tangíveis (na forma de recursos financeiros) e intangíveis (na forma de promoção de identificação ideológica) para a aproximação com outros Estados (Corrales; Romero, 2013). O cerne dessa estratégia era a ideia de que "oferecer generosas doações em nome da redistribuição social, juntamente com o emprego de uma ideologia anti-imperialista, pode elevar a estatura de uma nação" (Corrales; Romero, 2013, p. 17).

É nesse contexto que a Venezuela passa ser foco de preocupação diplomática dos EUA. A estabilidade da Venezuela (tanto em seu plano doméstico quanto no que se refere às relações bilaterais) era uma apreensão estadunidense, especialmente, por conta do fornecimento de petróleo para as refinarias do sul dos EUA. Ao final dos anos 
1990, a Venezuela se encontrava entre os cinco maiores exportadores de petróleo para os EUA. Além dessa questão energética, outros elementos que tornavam a estabilidade política venezuelana relevante para os EUA eram as questões de comércio, promoção da democracia e estabilidade na região da América do Sul, bem como a questão da própria segurança hemisférica (Lapper, 2006). Assim, a análise da forma como diferentes governos lidaram com essa problemática torna-se pertinente.

\section{GOVERNO BUSH: DA ASCENSÃO DE CHÁVEZ À CONSOLIDAÇÃO DO CHAVISMO ANTIESTADUNIDENSE}

Quando Chávez assumiu a presidência da Venezuela, ainda no período de governo de Bill Clinton (1993-2001), os EUA não investiram muita atenção a essa mudança política venezuelana. Durante o começo de seu mandato, Chávez focou seu trabalho em reformas institucionais na Venezuela. Ainda em 1999, foi convocada Assembleia Nacional Constituinte e nos dois anos subsequentes o governo ocupou-se com matérias relativas à reestruturação burocrática, política e econômica do país. Por conta disso, o governo Clinton acreditava que Chávez não teria "tempo ou recursos institucionais para converter sua preferência de política externa em políticas concretas capazes de ameaçar o governo dos EUA" (Corrales; Romero, 2013, p. 45). Nesse cenário, a opção de Clinton foi por não confrontar o discurso afrontoso de Chávez. Em vez disso, a diplomacia estadunidense optou por destacar o gap existente entre a retórica chavista e as ações concretas implementadas pelo governo. A máxima dentro do governo era "Watch what he does, not what he says" (Leogrande, 2007). Além de haver essa disparidade entre discurso e prática, a administração Clinton minimizava a possibilidade de a Venezuela representar uma ameaça por conta da dependência venezuelana de suas exportações de petróleo aos EUA (Lapper, 2006). Desse modo, do momento em que Chávez assumiu a presidência da Venezuela até o fim do mandato de Clinton, a diplomacia estadunidense minimizava o potencial risco que a Venezuela representava para os EUA.

É nesse contexto que George W. Bush é eleito em novembro de 2000. O discurso sobre política externa predominante durante a campanha de Bush era o de redução dos compromissos internacionais estadunidenses. Bush defendia que os EUA deveriam ter 
"humildade" em sua agenda internacional, isto é, ser mais seletivo em seu engajamento (Fonseca, 2008). No que concerne à América Latina especificamente, Bush chegou a anunciar uma nova era das relações entre os EUA e a região. Havia a promessa de que a América Latina deixaria de ser espaço "esquecido" pela diplomacia estadunidense e a plataforma de campanha falava em priorização das relações hemisféricas. A América Latina seria "compromisso fundamental" dos EUA (Hakim, 2006). Tendo sido governador do estado do Texas, Bush durante a campanha se projetava como político familiarizado com as questões envolvendo a América Latina, ainda que, notadamente, Bush não tivesse experiência com questões de política externa. Mas essa era uma estratégia republicana pela conquista de votos latinos (Fonseca, 2008).

Ao assumir a presidência, Bush acabou resumindo seu interesse pela América Latina a questões relativas ao México. De fato, a primeira viagem presidencial de Bush foi ao México, evento simbólico (United States of America - USA, 2019). Todavia, foi durante o governo Bush que a América Latina viveu um dos momentos de maior distanciamento aos EUA de sua história (Fonseca, 2008). Dois fatores referentes aos EUA podem ser apontados para tal fato: a conformação da equipe de formulação de política externa da administração Bush e os eventos internacionais que predominaram a agenda da diplomacia estadunidense no começo do século XXI, notadamente, a Guerra ao Terror. Esses dois fatores, naturalmente, tiveram implicações sobre a forma como os EUA lideram, especificamente, com a questão da Venezuela.

Corrales e Romero (2013) identificam três momentos da política externa dos EUA para a Venezuela durante o governo Bush. O primeiro deles é entre 2001 e 2003 no qual ocorre o reconhecimento por parte dos EUA da ameaça que a Venezuela chavista poderia representar aos ao país. Isso ocorre num momento em que Chávez intensifica seu discurso de oposição às políticas estadunidenses, sobretudo a partir da invasão do Afeganistão. Nesse momento, aconteceu um escalonamento nos discursos dos dois países e trocas de acusações entraram em pauta (Puente, 2013). Ainda assim, os EUA desferiram pouca atenção à Venezuela, que ocupava a posição de ameaça intermediária (Corrales; Romero, 2013). Os atentados de 11 de setembro de 2001 e a consequente Guerra ao Terror deixaram pouco espaço para outras questões na agenda prioritária 
dos EUA. A Venezuela, assim como o resto da América Latina, acabou marginalizada pela diplomacia estadunidense (Fonseca, 2008).

Entretanto, foi nesse ínterim que sucedeu um dos episódios mais marcantes envolvendo os EUA e a Venezuela. No começo de 2002, Chávez sofreu uma tentativa de golpe de Estado orquestrado por setores empresariais e das Forças Armadas. Em 11 de abril de 2002, Chávez foi detido por um grupo de militares venezuelanos que declararam a dissolução do Congresso e do Supremo Tribunal e a nulidade da Constituição de 1999. Contudo, o golpe foi frustrado em menos de 48h por conta da reação popular e pelo fato de militares leais à Chávez terem recuperado o controle do palácio presidencial de Miraflores. Não obstante, esse curto espaço temporal foi suficiente para suscitar reações de aversão ao golpe entre a comunidade internacional. Os EUA foram um dos únicos países a, nesse intervalo, reconhecerem o governo interino de Pedro Carmona (Avilés, 2005). Imediatamente após sua restituição, Chávez acusou os EUA de estarem por trás do episódio.

Hoje, sabe-se que, apesar de o corpo diplomático estadunidense não ter atuado diretamente na tentativa de golpe, indiretamente os EUA tiveram algum papel ao, em primeiro lugar, contribuir para o financiamento de grupos que articulavam o golpe ao longo de 2001 e, em segundo lugar, negar-se a manifestar oposição ao golpe mesmo quando os seus organizadores consultaram a representação estadunidense em Caracas sobre qual seria a posição dos EUA perante eventual ocorrência (Avilés, 2005; Leogrande, 2007). Oficialmente, o discurso diplomático estadunidense foi silencioso quando da eclosão do golpe, tentaram justificá-lo como reação legítima à tirania de Chávez e buscaram articular regionalmente o reconhecimento do governo golpista.

A partir de então, o tom do discurso de Chávez contra os EUA elevou-se acentuadamente. Após a tentativa de golpe, o governo Chávez ainda enfrentou, em 2004, um processo de referendo revogatório e não só saiu internamente fortalecido do episódio como também demonstrou que estava se consolidando como ator internacional de oposição aos EUA. Com o governo estabilizado, Chávez pode lançar-se internacionalmente. Buscou aproximação com os Castros em Cuba e estreitou relações com China, Rússia e Irã, numa estratégia que conciliava a oposição político-ideológica 
aos EUA e a diversificação de parcerias internacionais da Venezuela - que até então exportava 60\% de seu petróleo para os EUA - (Lapper, 2006). Naquela época, impulsionada pelo boom das commodities, a economia venezuelana tinha desempenho robusto, permitindo com que o governo chavista executasse políticas públicas de melhoria da qualidade de vida da população o que, por sua vez, garantia forte base de apoio popular à Chávez. Em dezembro de 2006, Chávez foi reeleito com mais de 60\% dos votos para mais um mandato de seis anos.

Nesse contexto, entre 2003 e 2007, Corrales e Romero (2003) identificam o segundo momento da política externa dos EUA para a Venezuela. Os EUA passaram a replicar as ações venezuelanas em sentido contrário. Foi o momento de "Tit-for-Tat". A conjuntura de intensificação da agressividade retórica chavista passou a ser respondida no mesmo tom pelos EUA. Do mesmo modo como a Venezuela aproximava-se bilateralmente de opositores dos EUA, os EUA também começaram a se aproximar de desafetos de Caracas (como foi o caso da aproximação com a Colômbia de Álvaro Uribe). Assim como a Venezuela construía alternativas multilaterais como a Aliança Bolivariana para os Povos de Nossa América (ALBA) e a PetroCaribe, os EUA também buscaram estabelecer novas alianças regionais na América Latina (embora esse aspecto multilateral não tenha sido bem-sucedido). Assim, os EUA adotaram justamente a postura que interessava à Venezuela: a confrontação (Corrales; Romero, 2013). Em 2006, o Departamento de Estado dos EUA a venda de bens e serviços de Defesa para a Venezuela por conta da falta de comprometimento do país com ações antiterrorismo (Sullivan, 2008).

O despertar dos EUA para a ameaça venezuelana a partir de 2001 e a intensificação das reações a partir de 2003 tem como uma de suas variáveis explicativas a composição do grupo de formuladores de política externa do governo Bush. Diferente do governo Clinton, no qual estiveram presentes muitos liberais internacionalistas, 0 primeiro governo Bush foi predominado por neoconservadores. Boa parte dos nomeados para cargos relativos aos assuntos hemisféricos tanto no Departamento de Estado quanto no Departamento de Defesa eram Cold Warriors, veteranos (como Otto Reich, Roger Noriega e Roger Pardo-Maurer) que haviam participado, sobretudo, do 
governo Reagan e que continuavam a pensar a política externa dos EUA em termos de amigos-inimigos (Leogrande, 2007; Fonseca, 2008). Foi durante esse período que a tensão entre EUA e Venezuela atingiu seu ápice. O marco simbólico desse momento é o discurso de Chávez no Debate Geral da Assembleia Geral das Nações Unidas em 2006, no qual ele afirmou que Bush deixou um rastro de enxofre e o chamando de "diabo" (CNN, 2006).

Ao final do segundo mandato de Bush a postura dos EUA modificou-se. Mudanças na equipe do Departamento de Estado foram significativas para tanto. Reich e Noriega foram substituídos por uma equipe comandada por Thomas Shannon. Àquela época, chamava a atenção a má avaliação que os latino-americanos faziam das políticas empreendidas pelos EUA. Além disso, o governo estadunidense sofria desgaste internacional mais amplo resultante de suas ações unilaterais no auge da Guerra ao Terror. Isto posto, a administração Bush reviu sua política para a Venezuela, iniciando o período de "Talk Softly, Sanction Softly, and keep watch" (Corrales; Romero, 2013). O gatilho para essa mudança foi o próprio discurso de Chávez na ONU em 2006. Após esse episódio, os EUA passaram a ponderar as ações de Chávez que mereciam respostas. Durante viagem de Bush pela América do Sul em março de 2007, Chávez incentivou protestos antiestadunidenses que foram sumariamente ignorados pela diplomacia de Bush, que preferiu enfatizar que a razão da visita ao subcontinente era o estabelecimento de uma agenda positiva com a região (Sullivan, 2008). Essa política foi considerada menos "alarmista" e focou em responder questões pontuais que oferecessem risco concreto aos interesses dos EUA. Ou seja, já desgastada ao final de seu mandato, a administração Bush deixou de responder aos ataques chavistas e adotou postura mais seletiva nas reações à Venezuela.

\section{GOVERNO OBAMA: DO AUGE DO GOVERNO CHAVISTA À ECLOSÃO DA CRISE}

Para as eleições presidenciais de 2008, o Partido Democrata indicou Barack Obama para concorrer à presidência como oposição à situação. Considerado candidato jovem e com pouca experiência na política de Washington, Obama construiu sua campanha sob o argumento de ser "mudança", de ser apto a levar "o novo" à Casa Branca. Nesse sentido, ao longo da campanha, Obama fez contundentes críticas à política externa 
empreendida por Bush. No que toca à América Latina, Obama proferiu o discurso "Renewing U.S. Leadership in the Americas" em maio de 2008 em Miami. Esse discurso tornou-se o principal documento de sua campanha referente à América Latina (Ayerbe, 2016). Na ocasião, "Obama buscou capitalizar o importante voto latino ao criticar o desempenho hemisférico de Bush, por ter sido 'negligente com nossos amigos, ineficaz com nossos adversários, desinteressado nos desafios que importam para as pessoas e incapaz de promover nossos interesses na região'" (Colombo; Frechero, 2012, p. 192). De certo modo, Obama reeditava o discurso de Bush em 2000, no qual se faziam críticas à forma de tratar as relações com os países da América Latina e fazia-se acusação de "abandono" da região. Todavia, o discurso de Obama funcionou e, quando eleito em novembro de 2008, emergiu na América Latina uma onda de esperança por um novo padrão de relacionamento com a potência hegemônica (Colombo; Frechero, 2012). As altas expectativas criadas por Obama durante sua campanha eram as de que os EUA reparariam os danos nas relações com a América Latina estabelecendo uma nova agenda e novas práticas para o relacionamento com a região (Buxton, 2011)

Do mesmo modo como se esperava um novo marco nas relações com a América Latina, a expectativa em relação à Venezuela era de que Obama iniciasse uma nova abordagem ao governo chavista. Chávez assistiu com cautela a ascensão de Obama à presidência em janeiro de 2009 (McCoy, 2011). Em seu discurso anual para a Assembleia Nacional no início de 2009, o presidente venezuelano declarou que esperava que com o governo Obama os EUA interrompessem - o que ele considerava agressões à Venezuela (Venezuela Analysis, 2009). Os primeiros sinais de que Obama estava, de fato, disposto a inaugurar uma nova política para a América Latina e, em específico, para a Venezuela ocorreram na $\vee$ Cúpula das Américas, ocorrida em abril de 2009 em Trinidad y Tobago (Ayerbe, 2016). Naquela oportunidade, Obama inclusive encontrou-se com Hugo Chávez, episódio no qual o líder venezuelano presenteou o chefe de Estado estadunidense com o livro As Veias Abertas da América Latina, de Eduardo Galeano (Halford, 2009). Um símbolo de distensão entre os dois países (Colombo; Frechero, 2012). Dois meses após o encontro cordial entre Obama e Chávez, EUA e Venezuela, silenciosamente, reintegraram seus respectivos embaixadores, os 
quais haviam sido chamados de volta aos seus países em meio a acusações envolvendo suposta interferência estadunidense em assuntos internos da Bolívia, grande aliado da Venezuela chavista (McCoy, 2011).

Entretanto, a lua-de-mel entre América Latina e Obama durou pouco. Ao longo de 2010 dois eventos deterioraram as relações dos EUA com a América Latina e com a Venezuela em específico. Em primeiro lugar, houve a crise em Honduras que levou à destituição do presidente Manuel Zelaya em junho de 2009. A América Latina foi praticamente unânime na condenação ao episódio. Os EUA destoaram ao não se oporem à formação de novo governo. Com isso, a administração Obama contrariou o discurso inicial de privilegiar a construção de consensos hemisféricos e, novamente, "subordinaram a convergência regional em favor de interesses estratégicos" (Ayerbe, 2016, p. 13). Em segundo lugar, houve a aproximação dos EUA com a Colômbia. Naquele momento, havia a forte suspeita internacional de que o governo chavista colaborava com as Forças Armadas Revolucionárias da Colômbia (FARC), o que gerava grande desconforto aos EUA. Assim, os EUA, em agosto de 2009, negociaram um acordo de cooperação em Defesa com a Colômbia no qual os EUA teriam acesso a bases militares colombianas, fato que gerou grande descontentamento na Venezuela (McCoy, 2011).

Um outro fator que atrapalhou o desenvolvimento das relações dos EUA com a Venezuela foi a demora em nomear os membros da equipe para assuntos hemisféricos no Departamento de Estado. Arturo Valenzuela foi designado como responsável pelos Assuntos Hemisféricos no Departamento de Estado apenas em maio e, por disputas políticas em meio aos trâmites no Congresso dos EUA, sua nomeação foi confirmada apenas em novembro de 2009 (McCoy, 2011). "Como resultado, no final do primeiro ano de gestão, já era palpável a ausência absoluta de uma nova política hemisférica [...] os eventos referidos foram dando suporte à ideia de uma continuidade fundamental no que diz respeito à negligência, à ineficácia e ao desinteresse, que haviam sido denunciados pelo próprio Obama em 2008." (Colombo; Frechero, 2012, p. 194).

Obama enfrentava um dilema administrativo. Se, por um lado, ele percebia a oportunidade de estabelecer um novo marco de relações com a América Latina e, dessa 
forma, reconquistar a influência estadunidense na região; por outro, ele sofria grandes resistências domésticas que balizavam seu potencial de inovação na política externa (Hellinger, 2011). "[...] até mesmo o modesto gesto de apertar a mão de Hugo Chávez suscitou uma enxurrada de condenações da mídia de direita, e quaisquer concessões significativas à América Latina [...] certamente gerariam uma resposta ainda mais reacionária de uma direita populista no Congresso revigorada pelas eleições de 2010." (Hellinger, 2011, p. 60). Não obstante, a própria administração Obama guardava apreensão em relação à Venezuela. Ainda em 2010, relatórios oficiais dos EUA começaram a indicar preocupações que assolavam a equipe de política externa de Obama. O National Intelligence Report demonstrava receio com a aproximação da Venezuela a China, Rússia e Irã, e o Annual Human Rights Report questionava ações venezuelanas que poderiam minar a democracia no país, como a politização do judiciário e a intimidação da oposição política e da imprensa de oposição (McCoy, 2011).

A política seguida por Obama mantinha as diretrizes do período final do governo Bush, com respostas e ações pontuais de oposição à Chávez e com a continuidade do monitoramento das ações do governo venezuelano. Conforme a então Secretária de Estado, Hillary Clinton, a posição dos EUA era de preocupação com as ações e a postura de Chávez, mas não se deveria exagerar a ameaça que ele representava (Sullivan, 2010). O governo Obama inclusive manteve as classificações anuais iniciadas, respectivamente, em 2005 e em 2006 de Venezuela como país que não cumpria os requisitos internacionais de combate ao narcotráfico e ao terrorismo (Sullivan, 2016).

Até aquele momento, a conjuntura Venezuelana era de conforto econômico e expansão das políticas sociais implementadas pelo chavismo. Mas, a partir de 2012, sinais de desgaste político do governo e da economia do país começaram a aparecer. Nas eleições presidenciais de 2012, a margem de vitória de Chávez (para seu quarto mandato) perante os oponentes foi reduzida se comparada às largas vitórias anteriores. Além disso, começaram a surgir indícios de alta na inflação do país. Também do ponto de vista econômico, a partir de 2013 e, sobretudo, em 2014 ocorreu uma considerável redução dos preços internacionais das commodities, especialmente, do petróleo, o que 
teve impacto direto e contundente sobre a saúde da economia venezuelana (Nelson, 2018).

Ainda assim, o fato venezuelano mais marcante desse período foi o falecimento de Hugo Chávez no dia 5 de março de 2013 em decorrência de um câncer. Foi a partir da perda da liderança forte de Chávez que se instalou uma crise generalizada na Venezuela. Somada à situação econômica fragilizada, as acusações de violações de direitos civis e políticos recrudesceram. A sucessão de Chávez foi, por si só, objeto de conflito entre o chavismo e a oposição. Conforme determina a Constituição venezuelana, foi realizada uma nova eleição presidencial na qual Nicolás Maduro Moros foi o representante chavista e venceu o pleito com uma estreita margem de 1,49 pontos percentuais (Carter Center, 2013). Então, houve um escalonamento das tensões que resultou em violentos protestos em 2014 e nos anos subsequentes (Taylor, 2014; Muñoz; Minaya, 2015; Buitrago; Oré, 2016). A Venezuela entrou em uma crise política, econômica, institucional e social generalizada, levando a grandes contingentes populacionais a emigrarem do país. Desde então, oposição e chavismo se encontram em disputa reivindicando suas respectivas legitimidade de governo, configurando um empate catastrófico (Hirst, 2019).

Sendo assim, Obama enfrentou nova situação em seu segundo mandato (20132017), já não mais enfrentando o desafio de lidar com Hugo Chávez, mas sim com uma crise venezuelana doméstica que gerou novos problemas para a diplomacia estadunidense. Com a morte de Chávez, por alguns instantes a administração Obama acreditou que o diálogo com a Venezuela seria facilitado. Em junho de 2013, o então Secretário de Estado dos EUA, John Kerry, chegou a se encontrar com o Ministro de Relações Exteriores da Venezuela (The New York Times, 2013). No entanto, logo as relações bilaterais se deterioraram novamente por conta da manutenção da retórica agressiva e das ações controversas por parte de Maduro (Sullivan, 2017). No mesmo ano, a Venezuela expulsou alguns dos diplomatas estadunidenses em Caracas sob a acusação de estarem trabalhando pela desestabilização do país. Os EUA responderam da mesma forma, expulsaram diplomatas venezuelanos de Washington. 
Entre 2014 e 2016, as relações entre EUA e Venezuela "continuaram a espiral descendente" (Sullivan, 2017, p. 31). Em 2015, Obama declarou a Venezuela uma ameaça nacional (The Huffington Post, 2015). Naquele ano, Obama instaurou a Executive Order 13692 determinando "sanções contra indivíduos que inibissem o processo democrático, cometessem violência ou abuso de direitos humanos, ou estivesse envolvido em corrupção" (Seelke, 2019, p. 2). Com essa atitude, Obama "impôs restrições de visto a mais de 60 funcionários venezuelanos atuais e anteriores responsáveis ou cúmplices de violações de direitos humanos (Sullivan, 2017, p. 50). O foco da política externa dos EUA era atacar as violações de direitos humanos, civis e políticos dentro da Venezuela e criticar as ações antidemocráticas do governo chavista. A resposta de Caracas continuou sendo a de que os EUA trabalhavam pela desestabilização da Venezuela e derrubada do governo Maduro, o que foi veementemente negado por Washington no decurso do governo Obama.

\section{CONSIDERAÇÕES FINAIS}

Do início do governo Bush (janeiro de 2001) ao final do governo Obama (janeiro de 2017), é possível identificar três grandes formas dos EUA tratar a questão da Venezuela. Num primeiro momento, de 2001 ao final de 2006, os EUA reagiram de maneira enérgica aos ataques retóricos venezuelanos, propiciando um embate discursivo direto com Hugo Chávez. Já num segundo momento, de fins de 2006 a 2013/2014, os EUA arrefeceram suas réplicas e mantiveram uma política externa mais contida, respondendo à Venezuela em questões pontuais, mas sem desprender o olho das ações contrárias aos interesses estadunidenses executadas por Caracas. No terceiro momento, a partir de 2014, a eclosão da ampla crise venezuelana favoreceu uma intensificação dos discursos e das ações de oposição à Venezuela por parte dos EUA. Nesse momento, Washington elevou o tom de suas críticas e passou a aplicar sanções.

Com isso, é possível identificar dois tipos de mudança na política externa dos EUA para a Venezuela recentemente. A primeira delas ocorreu no próprio seio do governo Bush, motivada por desgastes sofridos pela sua política externa internacionalmente e a consequente alteração da equipe que conduzia as relações hemisféricas. Ao assumir o 
governo, Obama deu continuidade à política do final do governo Bush. Ainda que tivesse a pretensão de melhorar as relações com a Venezuela, Obama sofreu restrições de ordem interna (setores de oposição domésticos) e de ordem externa (baixa disposição venezuelana em mudar seu posicionamento), optando então pela manutenção da política de Talk Softly, Sanction Softly. Já ao final do segundo mandato de Obama, é verificada a segunda mudança da política externa dos EUA para a Venezuela. Desta vez, determinada pela conjuntura venezuelana de crise, a qual demandou reações mais enfáticas dos EUA. Portanto, pode-se concluir que a forma como os diferentes governos trataram a questão venezuelana foi condicionada pelas conjunturas domésticas tanto de EUA quanto de Venezuela, que balizaram as pretensões diplomáticas iniciais de ambos os presidentes.

\section{REFERÊNCIAS BIBLIOGRÁFICAS}

Avilés, W. (2005) 'The Democratic-Peace Thesis and U . S. Relations with Colombia and Venezuela', Latin American Perspectives, 32(142), pp. 33-59. doi: 10.1177/0094582X05275744.

Ayerbe, L. F. (2016) 'Estados Unidos-América Latina: balance de la administración de Barack Obama al final de su segundo mandato', Anuario de Integración, (13), pp. 11-30.

Buxton, J. (2011) 'Forward into History: Understanding Obama's Latin American Policy', Latin American Perspectives, 38(178), pp. 29-45. doi: 10.1177/0094582X11406207.

CNN (2006) 'Chavez: Bush "devil"; U.S. "on the way down"'. Available at: http://edition.cnn.com/2006/WORLD/americas/09/20/chavez.un/.

Colombo, S.; Frechero, J. I. (2012) 'Yes We Can? A Política Externa de Obama para a América Latina: Da Decepção à Autonomização da Região', Contexto Internacional, 34, pp. 189-222.

Corrales, J.; Romero, C. A. (2013) U.S. - Venezuela Relations Since The 1990s. New York: Routledge.

Fonseca, C. (2008) 'O Governo George W. Bush e o relacionamento EUA-América Latina', Relações Internacionais, 19, pp. 147-158.

Hellinger, D. (2011) 'Obama and the Bolivarian Agenda for the Americas', Latin American Perspectives, 38(178), pp. 46-62. doi: 10.1177/0094582X11406209. 
Hirst, M. (2019) 'A crise na Venezuela e o enquadramento dos Estados Unidos: opções de política externa na América do Sul', palestra realizada na sede do Programa de PósGraduação em Relações Internacionais San Tiago Dantas (Unesp, Unicamp, PUC-SP), São Paulo, 12 de março de 2019.

Lapper, R. (2006) Living with Hugo: U.S. Policy Toward Hugo Chávez's Venezuela. Washington D.C.

Leogrande, W. M. (2007) 'A Poverty of Imagination: George W. Bush's Policy in Latin America', Journal of Latin American Studies, 39(2), pp. 355-385.

McCoy, J. (2011) 'The Chávez Challenge for Obama: An Inconvenient Marriage or Frosty Separation', in Lowenthal, A. F., Piccone, T. J., and Whitehead, L. (eds) Shifting the Balance: Obama and the Americas. Washington D.C.: Brookings Institution Press, pp. 69-85.

Nelson, R. M. (2018) Venezuela's Economic Crisis: Issues for Congress. Washington D.C.

Puente, U. V. (2013) 'Las relaciones entre Estados Unidos y la República Bolivariana de Venezuela: de la dependencia mutua a la emancipación', Trabajos y Ensayos, 17, pp. 116.

Romero, C. A. (2006) 'Venezuela y Estados Unidos: ¿una relación esquizofrénica?', Nueva Sociedad, (206), pp. 78-93.

Seelke, C. R. (2019) Venezuela: Political Crisis and U.S. Policy. Washington D.C.

Sullivan, M. P. (2008) Venezuela: Political Conditions and U.S. Policy. Washington D.C.

Sullivan, M. P. (2010) Venezuela: Issues in the 111 th Congress. Washington D.C.

Sullivan, M. P. (2016) Venezuela: Background and U.S. Relations. Washington D.C.

Sullivan, M. P. (2017) Venezuela: Issues for Congress, 2013-2016. Washington D.C.

Venezuela: Issues for Congress 2013-2016 (2017). Washington D.C.

\section{Fontes online}

Buitrago, D.; Oré, D. (2016) 'Maduro opponents march after Venezuela referendum sunk', Reuters. Available at: https://www.reuters.com/article/us-venezuelapoliticsidUSKCN12MOSY.

CNN (2006) 'Chavez: Bush "devil"; U.S. "on the way down". Available at: http://edition.cnn.com/2006/WORLD/americas/09/20/chavez.un/. 
Halford, M. (2009) 'The Book Chávez Gave Obama', New Yorker. Available at: https://www.newyorker.com/books/page-turner/the-book-chvez-gave-obama.

Muñoz, S. S.; Minaya, E. (2015) 'Shooting of Student Protester in Venezuela Ratchets Up Tension', The Wall Street Journal. Available at: https://www.wsj.com/articles/shootingof-student-protester-in-venezuela-ratchets-uptension-1424894647.

Taylor, A. (2014) 'Venezuela Gripped by Weeks of Anti-Government Protest', The Atlantic. Available at: https://www.theatlantic.com/photo/2014/02/venezuelagrippedby-weeks-of-anti-government-protest/100689/.

The Huffington Post (2015) 'Obama Declares Venezuela A Threat To U.S. National Security'. Available at:

https://www.huffpost.com/entry/obamavenezuela_n_6831890?guccounter=1.

The New York Times (2013) 'Kerry Meets With Venezuelan Foreign Minister'. Available at: https://www.nytimes.com/2013/06/06/world/americas/venezuela-frees-timtracyjailed-us-filmmaker-and-expels-him.html.

Venezuela Analysis (2009) 'Chavez Hopes Obama Stops US Aggression Against Venezuela'. Available at: https://venezuelanalysis.com/news/4112. 